\title{
AIDS and medical confidentiality
}

\author{
RAANAN GILLON
}

Consultants in sexually transmitted disease clinics dealing with patients with the acquired immune deficiency syndrome (AIDS) or positive for the human immunodeficiency virus (HIV) "are being over-protective of confidentiality," a general practitioner and member of the British Medical Association's central ethical committee is reported to have said. ${ }^{1}$ On the other hand, the BMA in its third and most recent statement on AIDS says, "The traditional confidentiality of the doctor-patient relationship must be upheld in the case of patients suffering from AIDS and HIV seropositive individuals." $"$

Clearly, the advice from the BMA is disputed by many general practitioners. The Leicestershire Local Medical Committee, representing 400 general practitioners, wrote to the BMA complaining that its guidelines were "very wrong"; as with any other serious illness general practitioners should be informed by specialists who discovered important medical information about their patients, including infection with HIV. ${ }^{3}$ In a straw poll three out of the four general practitioners questioned by a medical newspaper on this issue are reported to have opposed the BMA's policy and to have stated that general practitioners should be told. ${ }^{4}$ At the BMA's annual representative meeting this year a variety of motions demand that they shall be told. ${ }^{5}$ But in an excellent debate last week the annual conference of local medical committees, which represents all National Health Service general practitioners, rejected by 156 votes to 109 a proposal that family doctors had a right to be told if a patient was found to be positive for HIV and decided that patients were entitled to normal standards of confidentiality ( $p$ 1707).

The problem arises when people are found to be positive for HIV in a clinic for sexually transmitted diseases and refuse permission for the information to be passed on, despite advice about why it would be preferable for their general practitioner to be informed. The main justifications stated or implied in favour of breaking confidentiality in such circumstances are (1) that it is normal medical practice; (2) that it is in the interests of the patient by leading to better medical care; (3) that it is in the interests of the general practitioner and associated staff by reducing their risks of accidentally acquiring HIV infection; (4) that it may be in the interests of other patients who might risk becoming infected by the patient; and (5) that it is in the interests of society in general by helping to reduce the spread of the AIDS epidemic.

\section{Normal medical practice?}

Two questions need to be answered. Firstly, Is it normal medical practice to pass on medical information to other doctors against patients' wishes? Secondly, If it is, what follows?

\section{Imperial College of Science and Technology, London SW7 1NA}

RAANAN GILLON, MB, MRCP, director, health centre; editor, foumal of Medical Ethics; deputy director, Institute of Medical Ethics; and senior fellow, Centre for Law and Medical Ethics, King's College, London

To agree that specialists normally pass on information to patients' general practitioners in no way means that they normally do so when the patient refuses to allow such transfer of information about him or her. The fact that it is normal for specialists to pass on information to general practitioners surely only reflects the fact that in most cases patients agree, or can be reasonably assumed to agree, that it is in their interests for such information to be passed on. But when patients do not agree, or can reasonably be expected not to agree, then is it not also entirely "normal medical practice" for doctors to respect their patients' wishes? The two most obvious categories of such medical behaviour are when a patient is receiving psychotherapy or when a sexually transmitted disease has been diagnosed; the latter instance offers the most clearly relevant example in which it is precisely not normal medical practice for specialists to pass on medical information to general practitioners against the patient's wishes.

In any case, even if it were normal medical practice to pass on medical information against patients' wishes what would follow from this? Certainly not that the practice is therefore right. For it to be accepted right independent justification would be required, and the example of AIDS, as in so many other contexts, provides a stimulus for re-examining our normal practices. Some might argue (especially perhaps in other European countries) that to urge the breaking of confidentiality in cases of HIV positivity is a regrettable indication of how far we have already travelled down the slippery slope away from the absolute requirement of medical confidentiality demanded in the World Medical Association's international code of medical ethics ${ }^{6}$ and also apparently, but equivocally, in the new European guide to medical ethics? (equivocally because as well as requiring a guarantee to the patient of complete confidentiality the guide also provides for exceptions "where national law provides for exceptions"). The claim that medical confidentiality is an absolute requirement has been thoroughly presented by one contemporary European medical writer ${ }^{8}$ and in the face of erosions undoubtedly has its attractions. But, though I have argued previously that such absolutism is in the end untenable, ${ }^{9}$ medical confidentiality clearly remains a strong medicomoral principle and should be broken only if yet stronger moral reasons prevail. A mere claim that overriding confidentiality has become normal medical practice, even if it were true, would not provide moral justification for doing so.

\section{Is disclosure in the interests of the patient?}

Given that a patient, because he perceives his own interests to be best served by confidentiality, rejects the view of a clinician in a sexually transmitted diseases clinic that it would be preferable to tell his general practitioner of his disease, it would surely be unusually arrogant for a doctor to persist in assuming that "doctor knows best" and that disclosure is in the patient's best interests. A vital aspect of the medical objective of doing good for one's patients is to discount one's own perception of what is good for them in favour of their own, autonomous beliefs about what is good for them. Even in cases in which we believe that there is a clear discrepancy between 
what the patient autonomously desires and what is in the patient's best interests we have to be extremely careful in justifying imposing our beliefs on our patients in their interests when they explicitly reject such "help." A poignant example of reluctance to do so, even when death will be the outcome, was given by Sir Richard Bayliss, the patient being a Christian Scientist who refused medical treatment for thyrotoxicosis. ${ }^{10}$ Can justification "in the patient's best interests" be offered in this particular context of overriding confidentiality against the patient's will?

Three reported justifications are that if the general practitioner does not know of the patient's HIV positivity he may make wrong diagnoses, not treat the patient properly, or order potentially risky diagnostic tests. ${ }^{3}$ Of course there is a higher chance of wrong diagnosis and inappropriate treatment, but patients who are positive for HIV tend to maintain a continuing therapeutic relationship with the clinician at the clinic for sexually transmitted diseases who made the original diagnosis; thus even if the general practitioner does not pick up disorders related to AIDS the clinician at the clinic is likely to do so and treat them appropriately. As for potentially harmful diagnostic tests, I wonder which ones and in what sorts of circumstances. Thinking of the typical diagnostic tests in general practice that I request, such as radiography, blood tests, and urine tests, it is not clear to me how, if the tests were clinically in the patient's interests without my knowing about his HIV positivity, they would be transformed into being against his interests if I did know. In any case patients who did not wish me to know about their HIV positivity would probably consult their clinician at the sexually transmitted diseases clinic before undergoing special tests recommended by me such as contrast radiography. Thus it seems unlikely, from the point of view of the patient's best interests, that diagnostic tests would be a problem, and the problems of imperfect diagnosis and treatment by the general practitioner are likely to be compensated for by the continuing care of the specialist in sexually transmitted diseases.

Like most general practitioners I would regret such lack of confidence by the patient in me, but I do not believe that overriding his wishes for confidentiality is likely to improve matters or to be in his best interests. Even if I did I can certainly see no general justification in "the patient's best interests" for imposing such transfer of information to me against his will.

\section{Insurance medicals and patients' best interests}

In the context of best interests it is worth recalling that benefiting one's patients should also be considered in the context of the harm that a proposed benefit risks: it is net benefit over harm that counts. A patient's interests are not confined to strictly medical interests, and a proposed medical benefit may result in non-medical harms. A single example should suffice to demonstrate this. It is usually the general practitioner who is contacted for medical information when patients want life and health insurance. If the general practitioner knows about his patient's HIV positivity he must, presumably, in honestly and professionally answering the relevant question disclose this information. If, however, the general practitioner does not know he can honestly say so. Thus in some cases it may well be in the patient's best interests for the general practitioner not to know.

Here, incidentally, is another example in which our current medical norms - those concerning insurance medicals-are called into stark relief by the AIDS epidemic. It seems clear that when we complete an insurance medical form we use information gathered in the course of a therapeutic relationship for an essentially commercial purpose, and this commercial purpose is in some cases likely to conflict with the best interests of the patient. It is of course done with consent, but the sort of consent that the patient in many cases would prefer not to have to give. Perhaps we ought to change our norms so that in all cases in which there is any doubt in the general practitioner's mind about whether completing an insurance medical questionnaire would be in the patient's best interests (1) the patient should be consulted and (2) if the patient prefers the general practitioner should return the insurance medical form uncompleted. The company could then arrange for an independent and explicitly "non-therapeutic" medical assessment. In addition, the choice of having an independent medical assessment should perhaps be explicitly offered by insurance companies to all applicants for insurance right from the start.

\section{Is disclosure in the interests of general practitioners and other members of the primary care team?}

This is essentially the argument that confidentiality is too dangerous for general practitioners and other primary care health workers including nurses to respect in cases of HIV positivity. I considered the arguments of danger in a previous article about refusal to treat patients with AIDS and those positive for HIV. "In summary, I argued (1) that the medical profession (including "the greater medical profession") accepted a certain degree of risk as part of its professional norms and (2) that the extensive empirical evidence currently available showed that the probability of accidental transmission of HIV to medical staff and families and other close contacts of patients positive for HIV or with AIDS was very low, given normal care with blood and other body fluids.

\section{Is disclosure in the interests of other possible patients?}

I find this the most difficult of the arguments in favour of breaking confidentiality, though at most it seems to justify disclosure against a patient's will only in exceptional circumstances. Thus if either a clinician in a sexually transmitted diseases clinic or a general practitioner knows or has strong reason to believe that a patient positive for HIV intends to have sexual intercourse with a new and uninfected partner or partners without telling the partner(s), and efforts to persuade the patient to tell have been rejected and there is a reasonable prospect of preventing the event(s), then efforts to inform such contacts do seem justifiable in order to try to prevent them from being infected with what is likely to be a fatal virus. This seems particularly clearly justified if the previously uninfected contact is also a patient of the doctor concerned (because of the special obligations doctors have to their patients), but it might also apply, for example, in the context of tracing contacts of patients with sexually transmitted diseases as part of a general concern to protect others from potentially fatal diseases.

Even against this very limited justification of breach of confidentiality, however, it might be argued, as I do below, that it is still better not to break confidentiality. Thus by being known to maintain a very strict level of confidentiality the medical profession has a better chance of maintaining the trust of high risk groups; it will therefore be better able to influence them and more effectively protect the health of others in general. Although I would agree that it is almost always likely in practice that preserving confidentiality will be the better course for precisely such consequentialist justification I find it impossible to rule out circumstances in which I, at any rate, would believe it right to break confidentiality. I can imagine, for example, a "psychopath" positive for HIV who makes it clear that he or she does not care about transmitting the virus to others, and indeed intends to do so, and when I know that another of my patients, probably uninfected with HIV, is a likely new partner.

The possible existence of such rare exceptions (for most patients positive for HIV like most other patients and people in general are not psychopaths and do care about others) is simply evidence for my earlier claim that medical confidentiality should not be an absolute requirement, only a very strong one. In the context of a just society strong evidence of likely and preventable death or severe injury to others can afford justification for overriding confidentiality, including the passing on of information between doctors and to new contacts. But such circumstances will be extremely rare. In most cases the probability of preventing death or severe injury by breaking medical confidentiality about HIV state will be low-and 
every time a doctor does break such confidentiality he or she will further reduce a trust in the profession that while it exists can itself be reasonably expected to help reduce the spread of the disease.

\section{Is disclosure in the interests of society?}

The final argument sometimes offered for passing on information about patients positive for HIV is that it is in the interests of society by helping to reduce the spread of AIDS. Justice, it might be added, requires doctors to take into account not only the interests of their individual patients of the moment but of society in general. Though the desire to minimise the spread of AIDS is doubtless shared by all sane people, and though the claim that doctors must include the interests of society in their medicomoral reasoning is one that I would strongly support, it does not follow that overriding the traditional norms of medical practice in the context of AIDS is the best way to achieve those objectives. I hope to return to this theme in a subsequent paper, but, in brief, the spread of AIDS seems most likely to be curtailed and the interests of society best served if the trust and cooperation of those at greatest risk can be obtained and maintained. Thus the consequentialist objective of minimising the spread of AIDS fortunately seems to point in the same direction as the traditional rules of medical deontology, including the norms of medical confidentiality. In the context of this paper it seems particularly implausible to argue that the spread of AIDS will be curtailed if specialists in sexually transmitted diseases are routinely required to break medical confidentiality by passing on to general practitioners information about patients' HIV positivity against those patients' wishes. On the contrary, it seems far more probable that the interests of society will be best served if the medical profession in general, and perhaps specialists in sexually transmitted diseases in particular, can preserve their reputation, especially among those most at risk of infection, for conforming to a very strong-though not absolute-principle of medical confidentiality.

\section{Summary}

In summary, I have argued that the arguments offered or hinted at in favour of doctors' breaking medical confidentiality by passing on information about their patients' HIV state to others, including other doctors, when this is against the patient's considered wishes are generally unconvincing. Although in highly exceptional cases there may be justifications for overriding confidentiality, the requirement of medical confidentiality is a very strong, though not absolute, obligation. Patients, their contacts, doctors and their staff, and the common good are most likely to be best served if that tradition continues to be honoured.

\section{References}

1 Duncan N. GPs demand to be told results of AIDS tests. Pulse 1987; Jan 3:1.

2 British Medical Association. Third BMA statement on AIDS. London: BMA, 1986

3 Beecham L. Support for confidentiality for AIDS patients. Br Med f 1987;294:1177.

4 Kennard N. Should GPs be told AIDS test results? Pulse 1987; Jan 17:25.

4 Kennard N. Should GPs be told AIDS test results? Pulse 1987; Jan 17:25. British Medical Association. Agenda of the British Medical Association's annual
meeting 1987, motions 359-374. Br Med f 1987;294 (insert in issue of 6 June).

6 British Medical Association. Handbook of medical ethics. London: BMA, 1984:70-1.

7 Anonymous. European guide to medical ethics. IME Bulletin 1987; No 25:3-7.

8 Kottow MH. Medical confidentiality: an intransigent and absolute obligation. $\mathcal{J}$ Med Ethics 1986;12:117-22.

9 Gillon R. Confidentiality. Br Med $\mathcal{J}$ 1985;291:1634-6.

10 Bayliss R. A health hazard. Br Med f 1982;285:1824-5.

11 Gillon R. Refusal to treat AIDS and HIV positive patients. Br Med f 1987;294:1332-3.
$\mathrm{H}$ AVING a newsworthy subject may hinder researchers' chances of getting the right message across in the media. To launch the Study of Triplet and Higher Order Births (page 1696) we put out a press release entitled "The trials and tribulations of triplets." We aimed at telling parents that the study had started and that we would eventually be writing to ask about their experiences of bringing up three or more babies at once.

A freelance journalist offered to write an article that she hoped the Independent would publish. She wrote a feature article that gave a fuller picture of most of the points in our press release. It also highlighted instances of multiple births to women who had undergone in vitro fertilisation in private clinics and who then moved over to the NHS to deliver babies who spent long periods in intensive care. This issue had just been aired in the Lancet. The article also mentioned how the neonatal unit in Cambridge had been disrupted by sextuplets born to a woman who had been prescribed infertility drugs for anorexia nervosa.

The Independent, it so happened, already had a feature article on neonatal intensive care for the day in question, and so the editors changed our journalist's piece into a news story. Although the details of the changes were agreed with her, she may not have been aware of how the emphasis had changed. The article appeared with the title "Rise in multiple births puts other babies at risk," and the opening paragraph was: "Triplets, quins, and quads are now born so frequently as a result of fertility drugs that they are becoming a problem to hospital and social services. Cots in special care baby units are suddenly blocked after a multiple birth, putting other babies at risk (16 June, p 7)." Our contact address for parents, which the Independent had agreed to reinstate, did not appear in the article.

Meanwhile, one of the mothers of triplets on our steering group was invited to go on TV AM to talk about her work with the study and her personal experiences with her triplets. The interviewer focused, however, on her individual infertility treatment and gave her little chance to talk about the survey. Feeling frustrated by this experience, she then read the Independent article and was upset by how the headline seemed to blame women who had multiple births after taking infertility drugs. Such women are often made to feel that they are personally responsible for their plight and that they do not therefore deserve help from overstretched health and social services.

We decided to write a letter to the Independent pointing out that it is not known how far in vitro fertilisation and infertility treatment have contributed to the rise in the proportion of pregnancies resulting in multiple births. Nor do we know to what extent intensive care places are taken up with these babies. These are just two of the many questions our survey hopes to answer. The Independent did not publish our letter, which also included the missing address of the study.

Subsequent reports that have filtered through to us suggest that our message has been well and truly lost. At least one report said that our survey is now complete, when the press release said it was just starting. As a result of our press release and the Independent article a Cambridge paediatrician was interviewed on Radio 4's Today and Radio 1's Newsbeat but did not mention any need for the information we are trying to collect; rather he called for $£ 2 \mathrm{~m}$ to be spent on neonatal intensive care. Thus our plea for people to help with our study was changed into a plea for money for intensive care, and yet one of our main concerns is that money be spent on the less glamorous activity of supporting parents who have the difficult job of bringing up three or more children at once.

ALISON MACFARLANE, statistician, National Perinatal Epidemiology Unit, Radcliffe Infirmary, Oxford OX2 6HE. 